\title{
A Preliminary Analysis of Lake Level and Water Storage Changes over Lakes Baikal and Balkhash from Satellite Altimetry and Gravimetry
}

\author{
Cheinway Hwang *, Yu-Chi Kao, and Natthachet Tangdamrongsub \\ Department of Civil Engineering, National Chiao Tung University, Hsinchu, Taiwan
}

Received 24 February 2010, accepted 19 May 2010

\begin{abstract}
Lakes Baikal and Balkhash are two of the world's major lakes affecting fresh water supplies in their catchments. Measurements from satellite altimetry (TOPEX/Poseidon, Jason-1 and -2), satellite gravimetry (GRACE) and a hydrological model (LDAS) are used to see the relationship between lake level change (LLC) and water storage change in these two lakes. At Lake Baikal, the average rate of LLC is negative for 1992 - 1998 and positive for 1998 - 2007, and the reversal of the LLC trend concurs with that of the temperature trend during the 1997 - 1998 El Niño. The rate of gravity change ranges from - 0.5 to $0.5 \mu \mathrm{gal} \mathrm{yr}^{-1}$ with a low over the Tian Shan and a high over western Lake Baikal. Due to the climates over the two lakes, the phases of the annual gravity changes differ by up to 100 days. Using the rates of LLC and gravity changes, the ratios between the mass changes of the lake and its catchment over Lakes Baikal and Balkhash are estimated to 0.6 and 0.3, respectively. The result may help to establish water balance models over these two lakes.
\end{abstract}

Key words: Baikal, Balkhash, Lake level, GRACE, Gravity change, TOPEX/Poseidon

Citation: Hwang, C., Y. C. Kao, and N. Tangdamrongsub, 2011: A preliminary analysis of lake level and water storage changes over Lakes Baikal and Balkhash from satellite altimetry and gravimetry. Terr. Atmos. Ocean. Sci., 22, 97-108, doi: 10.3319/TAO.2010.05.19.01(TibXS)

\section{INTRODUCTION}

In many regions of the world, fresh water supply depends on a lake. The variation of the lake's level and the variation of the water storage in the lake's catchment are two critical parameters in the water balance equation of the lake basin (Bedient and Huber 2002; Gordon and Famiglietti 2004). A well understanding of these two parameters is essential for the water management of such a lake system. For dedication to this TAO special issue, we select Lake Baikal (Siberia) and Lake Balkhash (central Asia) in this paper for a case study of lake level and water storage changes over these two lake systems. Table 1 compares relevant information related to the two lakes. Figure 1 shows the terrains and river systems over these two lakes. Lake Baikal is located in Siberia and it has an extreme continental climate with a long, very cold and dry winter and a short cool summer. There are 336 rivers in the water catchment flowing into Lake Baikal with just one outgoing river (Angara River) flowing north to the Arctic. Lake Baikal is completely sur-

\footnotetext{
* Corresponding author

E-mail: cheinway@mail.nctu.edu.tw
}

rounded by mountains, and there are 22 small islands over the lake. With little influence by human activities, the water balance at Lake Baikal is largely affected by climate change. Furthermore, part of the Lake Baikal watershed is covered with permafrost and the lake surface is covered with ice from November to April.

With a closed water catchment, Lake Balkhash belongs to the dry continental climate. Lake Balkhash is an important water resource for Kazakhstan. It has no outgoing river. The lake level in Lake Balkhash is largely governed by human activities. Lake Balkhash is the $16^{\text {th }}$ largest lake in the world. Based on lake gauge records, the lake level of Lake Balkhash dropped by $2.2 \mathrm{~m}$ from 1970 to 1987 (Kezer and Matsuyama 2006). The Kazakh upland to its north has a semi-arid climate. The Saryesik-Atryan desert lies south of Lake Balkhash. Lake Balkhash can be divided into two parts. The western part of Lake Balkhash contains fresh water, with Ili River contributing to most of the water. The eastern part of Lake Balkhash contains saline water and the major water sources are Kazakh River and Aqsu River. Due to the arid and semi-arid climates surrounding Lake Balkhash, high evaporation rates occur here. The high 
development of agriculture activities along Ili River and Karatol River accelerates the water loss in Lake Balkhash. The inflow of Ili River to Lake Balkhash was $15 \mathrm{~km}^{3}$ in 1970 and was reduced to $7 \mathrm{~km}^{3}$ in 2003 due to the construction of Kapshaghay Hydroelectric power station in the 1970s. The $7 \mathrm{~km}^{3}$ volume accumulation is in fact less than the mass of evaporation.

Satellite altimetry data can be used over land and bodies of water. Typical altimetric applications for ocean observations include ocean circulation, ocean tide, marine gravity and sea level change. Two typical land applications of altimetry are LLC (Birkett 1995, 1998; Hwang et al. 2005) and the determination of land elevation (Berry et al. 1997); a recent compilation of such applications can be found in Hwang et al. (2008). Several passes of the TOPEX/Poseidon (T/P), Jason-1 and -2 ground tracks pass through the two lakes, and the sizes of the lakes are sufficiently large (see Table 1) to yield accurate height measurements from radar altimeters without waveform retracking. Direct uses of lake surface heights (LSHs) from Geophysical Data Records (GDR) of altimeter without further processing have been demonstrated by, e.g., Birkett $(1995,1998)$ and Hwang et al. (2005). A recent review of lake level studies using satellite altimetry is given by Crétaux and Birkett (2006).

The GRACE mission (Tapley et al. 2004) was launched in 2002 and has delivered gravity data for a wide range of applications in earth sciences. Examples of hydrological applications of GRACE gravity are given in, Chen et al. (2004), Davis et al. (2004), Wahr et al. (2004), Andersen and Hinderer (2005), and Swenson and Wahr (2009). As shown in Chambers et al. (2004) and Swenson and Wahr (2006), there exist large uncertainties in the GRACE-derived temporal gravity fields. Evident stripe patterns exist in the GRACE gravity fields and filtering should be applied before

Table 1. Comparison of selected features over Lake Baikal and Lake Balkhash.

\begin{tabular}{l|ll}
\hline Lake & Baikal & Balkhash \\
Area of water catchment in $\mathbf{k m}^{2}$ & 590000 & 413000 \\
Climate & Subarctic/contin-ental & Arid/semiarid \\
No. of primary inflow rivers & 336 & 7 \\
No. of outflow rivers & 1 & 0 \\
Average depth in m & 740 & 6 \\
Average elevation above sea level in $\mathbf{m}$ & 456 & 341 \\
Population in catchment area & 5060000 & 2500000 \\
Frozen period over lake & January - May & November - April \\
\hline
\end{tabular}

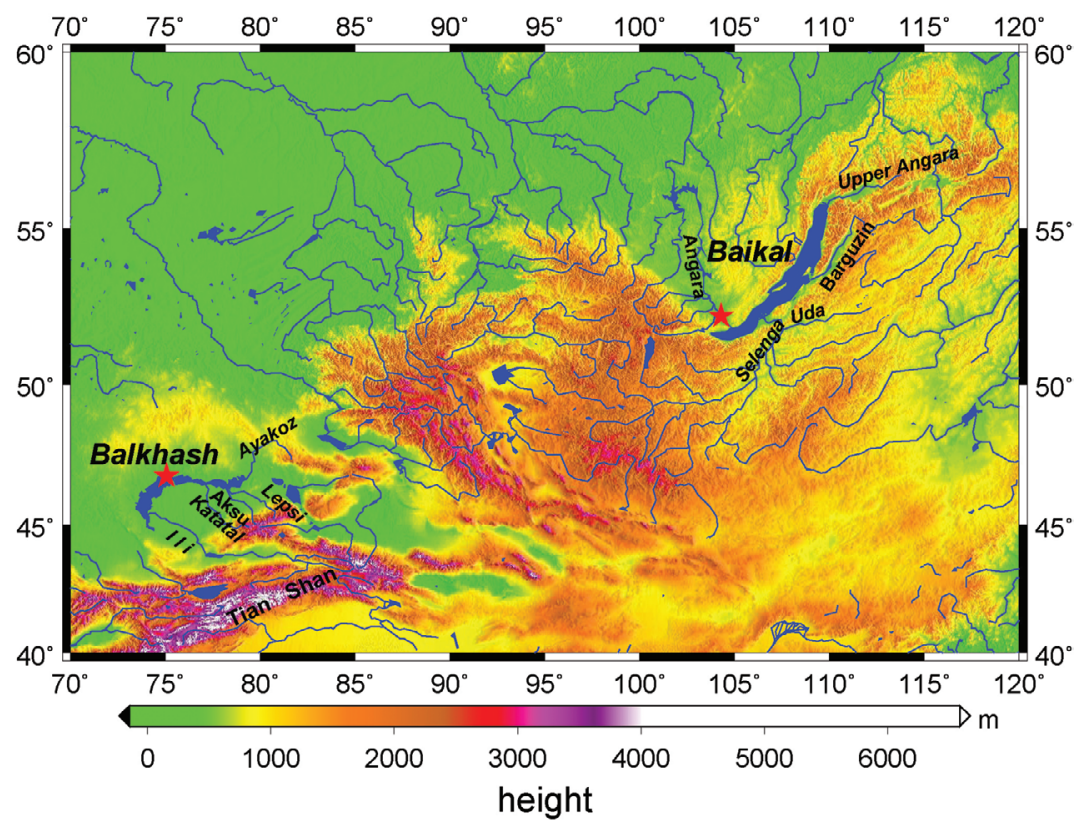

Fig. 1. Terrain and rivers over Lake Baikal (top) and Lake Balkhash. Stars show the temperature stations. 
applications (Swenson and Wahr 2006). However, filtering and de-striping will reduce the spatial resolution of GRACE gravity. As shown in Table 1, the areas of water catchments of Lake Baikal and Lake Balkhash are $590000 \mathrm{~km}^{2}$ (Vyruchalkina 2004) and $413000 \mathrm{~km}^{2}$ (Kezer and Matsuyama 2006), respectively, which are sufficiently large for applying the filtered temporal gravity from GRACE. For validation, the gravity changes from GRACE will be compared with those from a hydrological model. The relations among LLC, gravity change and climate change over the two lakes will be investigated.

The objective of this paper is to determine LLC from satellite altimetry and water storage change from satellite gravimetry (GRACE) over Lakes Baikal and Balkhash. A preliminary analysis of climate change based on comparisons of LLC and gravity changes with the changes in several climate parameters will be presented in the hope that the result from such comparisons may help to further understand the water balances in these lake systems.

\section{LAKE LEVEL CHANGE FROM SATELLITE ALTIMETRY}

In this paper, LSHs data for Lakes Baikal and Balkhash are from Department of Agriculture, USA, at the internet address http://www.pecad.fas.usda.gov/cropexplorer/global reservoir/. These LSHs are based on the satellite altimeter measurements collected by the missions TOPEX/Poseidon (01/1993 - 10/2002), Jason-1 (10/2002 - 12/2008) and Jason-2 (01/2009 - present). Jason-1 and -2 are the follow-on missions of $\mathrm{T} / \mathrm{P}$ and have the same repeat ground tracks of the latter (off by $1 \mathrm{~km}$ at most). Figure 2 shows the satellite passes of T/P that travel through the two lakes. For generating a time series of LSHs over a lake, an optimal reference point along a pass was chosen, so that the repeat height measurements from the 10-day cycles are free from radar waveform contamination of land, and the radiometers and the dual-frequency altimeters function properly to deliver optimal wet tropospheric and ionospheric corrections. In this paper, Pass 62 and 90 are selected for Lake Baikal and Lake Balkhash, respectively. The locations of the reference points are shown in Fig. 2. For each lake, the LSHs from the 10-day repeat cycles over a selected latitude range were reduced to the reference point of the lake. The latitude ranges for Lake Baikal and Lake Balkhash are $51.76^{\circ}-51.54^{\circ}$ and $46.44^{\circ}-46.69^{\circ}$, respectively. Suspicious raw LSHs were removed by using the median-filtered LSHs for checking anomalous values.

In this paper, the following corrections were applied to raw measurements of LSHs from T/P, Jason-1 and -2:

(1) Dry tropospheric and wet tropospheric corrections based on radiometer measurements.

(2) Ionospheric delay from dual-frequency altimeters.

(3) Solid earth tide and pole tide.

(4) Electromagnetic (EM) bias based on 2.3 percent of the significant wave height.

Because the two lakes are sufficiently large, radiometer and dual-frequency altimeter measurements will not be contaminated, so that the tropospheric correction and ionospheric correction can be made based on such measurements; however, over small lakes such as those in Tibet, radiometer and dual-frequency altimeter measurements will not always be available. The EM bias is due to wave height and this (a)

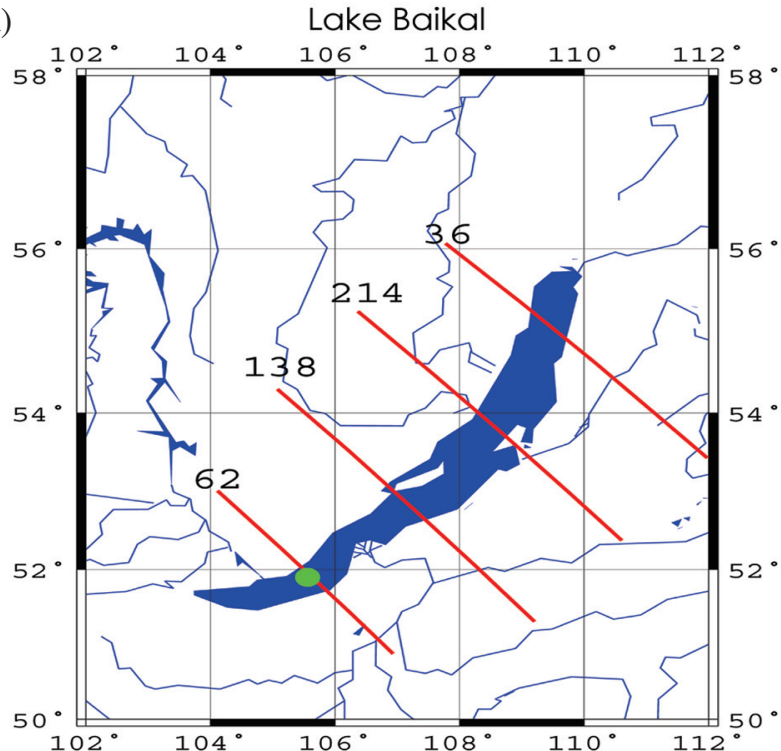

(b)

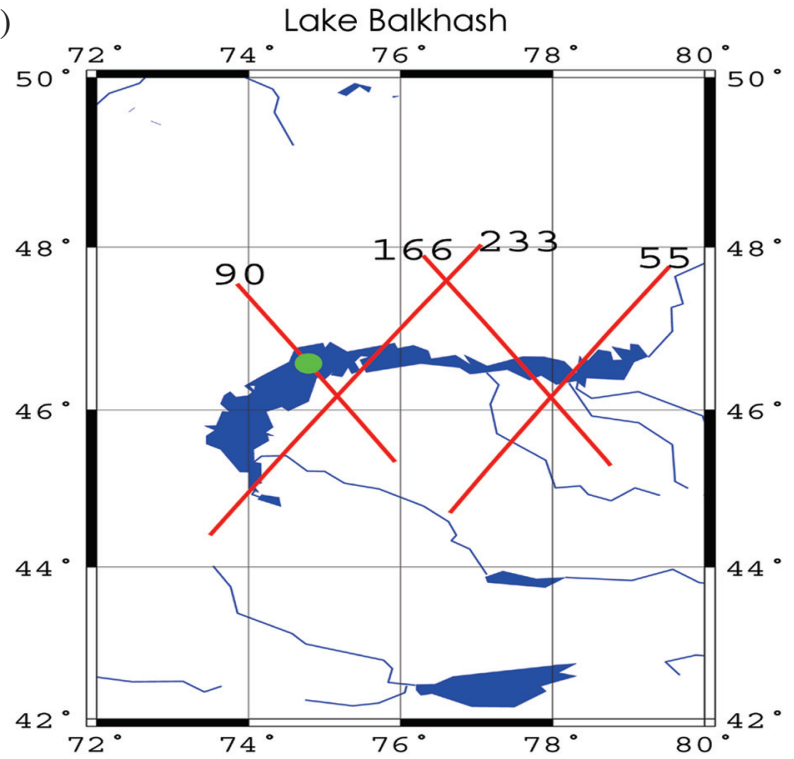

Fig. 2. Passes of T/P over Lake Baikal (a) and Lake Balkhash (b). The green dots along pass 62 (Lake Baikal) and 90 (Lake Balkhash) are the reference point for generating time series of lake level. 
correction should also be applied to measurements for large lakes such as Lakes Baikal and Balkhash. Lake tides over these lakes are believed to be small ( $\mathrm{cm}$ level) and were neglected.

The accuracies of LSHs in this paper vary, and depend on factors such as geophysical correction models and the surface properties of the lake (ice-covered and ice-free) in different seasons. A document in the data source (Department of Agriculture) indicates that several experiments have been made to indentify different lake measurement accuracies in different situations. Based on comparisons over lakes and reservoirs in North America, the accuracies of LSHs in this paper are believed to range from 4 to $7 \mathrm{~cm}$ over the Great Lakes, provided that outliers are removed. Over smaller lakes such as Lake Winnebago (area: $550 \mathrm{~km}^{2}$ ) and Lake of the Woods (area: $1900 \mathrm{~km}^{2}$ ), the uncertainties increase to $25-30 \mathrm{~cm}$. At higher latitudes such as Lake Baikal and Balkhash, lake surfaces are covered by ice over certain periods of time, and the height measurements by altimetry will be higher than the case of ice-free lake surfaces. In theory, range measurements over ice-covered lake surfaces should be corrected for errors in tracking gates of waveform because the normal tracking mode in an ocean altimeter is designed for the case of ice-free waters. If height measurements of lakes over ice surfaces are corrected using retracked gates, lake level accuracy from altimetry will be improved. Since our interest is the trend and the inter-annual change of lake level, waveform retracking was not carried out in this paper, but will be a subject of future study.

Figure 3 shows the 10-day lake level changes (LLCs) over Lakes Baikal and Balkhash. A LLC is defined as the difference between the 10-day repeat LSH and the mean LSH over the period of investigation. Some repeat cycles simply did not deliver altimeter measurements along the selected passes over the two lakes, leading to missing LLCs in Fig. 3. Missing altimeter measurements occurred in Jason-1 and -2 more frequently than T/P (see the records after 2002). The LLCs in Fig. 3 contain intra-seasonal, seasonal and inter-annual variations. Over Lake Baikal, the highs of LLCs occur in September or October with lows in March or April. For Lake Balkhash, the highs and lows occur in May-June and December-January, respectively. More analysis will be provided later.

The rates of LLC of the two lakes in Fig. 3 have different values over different periods of time. Table 2 lists the rates at selected periods. Over Lake Baikal, there are four different rates between October 1992 and October 2007. Since October 1992, the level of Lake Baikal increased at a rate of $6.7 \mathrm{~cm} \mathrm{yr}^{-1}$, reaching a maximum value in October 1994, which is also the highest between October 1992 and October 2007. From October 1994 to October 1996, the level of Lake Baikal decreased at a rate of $-27.3 \mathrm{~cm} \mathrm{yr}^{-1}$. Considering the area of Lake Baikal (Table 1), this decrease is equivalent to a water loss of $8.66 \mathrm{~km}^{3} \mathrm{yr}^{-1}$. Over Octo- ber 1996 - October 2003, the level of Lake Baikal increased steadily at a rate of $0.5 \mathrm{~cm} \mathrm{yr}^{-1}$, but the rate changed to $2.1 \mathrm{~cm} \mathrm{yr}^{-1}$ since October 2003.

Lake Balkhash also experienced different rates of LLC over 1992 - 2007. From October 1992 to April 1995, the level of Lake Balkhash increased at a rate of $18.8 \mathrm{~cm} \mathrm{yr}^{-1}$, but the level over 1995 - 1998 decreased at rate of $-14.1 \mathrm{~cm} \mathrm{yr}^{-1}$. From April 1998 to April 2005, a relatively large positive rate of change, $23.0 \mathrm{~cm} \mathrm{yr}^{-1}$, occurred, followed by a decreasing trend at $-3.6 \mathrm{~cm} \mathrm{yr}^{-1}$ through 2007. Compared to Lake Baikal, which is situated in a sparsely populated zone, the influence of man-made activities such as irrigation around Lake Balkhash is greater. If the decreasing trend of lake level at Lake Balkhash continues at the current rate $\left(-3.6 \mathrm{~cm} \mathrm{yr}^{-1}\right)$, Central Asia may suffer a shortage of water in the future.

\section{EQUIVALENT WATER HEIGHT CHANGE FROM GRACE DATA AND COMPARISON WITH THE LDAS MODEL}

In this paper, equivalent water height $(\mathrm{EWH})$ changes over Lake Baikal and Lake Balkhash were derived from the satellite mission GRACE. Specifically, gravity changes from August 2002 on were derived from the gravity harmonic coefficients (Stokes coefficients) of the Version GSM-RL04 monthly models of GRACE. The GSM-RL04 in this paper is based on some weighted mean of the GRACE gravity products of Center of Space Research (CSR), University of Texas, Austin, Jet Propulsion Laboratory (JPL), and GeoForschungsZentrum (GFZ) (Chambers et al. 2004). Corrections due to the gravity effects of solid tide, ocean tide and atmosphere were applied to the raw GRACE gravity fields. At a given location of a spherical earth, the EWH can be derived from gravity change as (Wahr et al. 1998; Hwang and Kao 2006).

$$
\begin{aligned}
h(\phi, \lambda)= & \frac{a_{E} \rho_{E}}{3 \rho_{W}} \cdot \sum_{n=0}^{n \max } \frac{2 n+1}{1+k_{n}} \\
& \cdot \sum_{m=0}^{n}\left[\bar{a}_{n m} \cos (m \lambda)+\bar{b}_{n m} \sin (m \lambda)\right] \bar{p}_{n m}(\phi)
\end{aligned}
$$

where $k_{n}$ is the loading Lover number of degree $n, \phi$ and $\lambda$ are latitude and longitude, $\bar{a}_{n m}$ and $\bar{b}_{n m}$ are harmonic coefficients of gravity change and $\bar{p}_{n m}$ is associated Legendre function of degree $n$ and order $m, \rho_{E}$ and $\rho_{W}$ are the densities of earth's crust and water, which take the values 5517 and $1000 \mathrm{~kg} \mathrm{~m}^{-3}$ in this paper.

There are both random and systematic errors in the GRACE gravity fields (Tapley et al. 2004; Wahr et al. 2004). Without a proper filtering, prominent stripes in the GRACE gravity fields will occur (Swenson and Wahr 2006). Several methods can be used to remove such stripes, e.g., the 
Gaussian filter (Jekeli 1981; Wahr et al. 1998), an anisotropic filter based on the calibrated error spectrum (Han et al. 2005); an optimal filter based on a priori estimates of signal and measurement error variances (Seo and Wilson 2005). In addition, there exist considerable correlations among some gravity harmonic coefficients, which might be reduced using a polynomial-fit method (PFM). In this paper, a PFM method based on the results of Swenson and Wahr (2006) and Chambers et al. (2006) was applied to original GRACE gravity harmonic coefficients before filtering. The method of filtering is the Gaussian mean filter (Jekeli 1981; Wahr et al. 1998), and a 5-dgree polynomial for correlation reduction is used. For the filtering, a harmonic coefficient of degree $n$ is scaled by a degree-dependent coefficient satisfy- ing the following recursive formula:

$$
\beta_{n+1}=-\frac{2 n+1}{a} \beta_{n}+\beta_{n-1}, \quad n \geq 1
$$

With the starting values at degree 0 and 1

$\beta_{0}=0, \beta_{1}=\frac{1+e^{-2 a}}{1-e^{-2 a}}-\frac{1}{a}$

where $a=1 / \psi, \psi=\left(2 \pi / N_{\max }\right)^{2}$ and $N_{\max }$ is the maximum degree of expansion.

Filtering and correlation-reduction will lead to loss of some gravity signatures contained in the original data (Chen
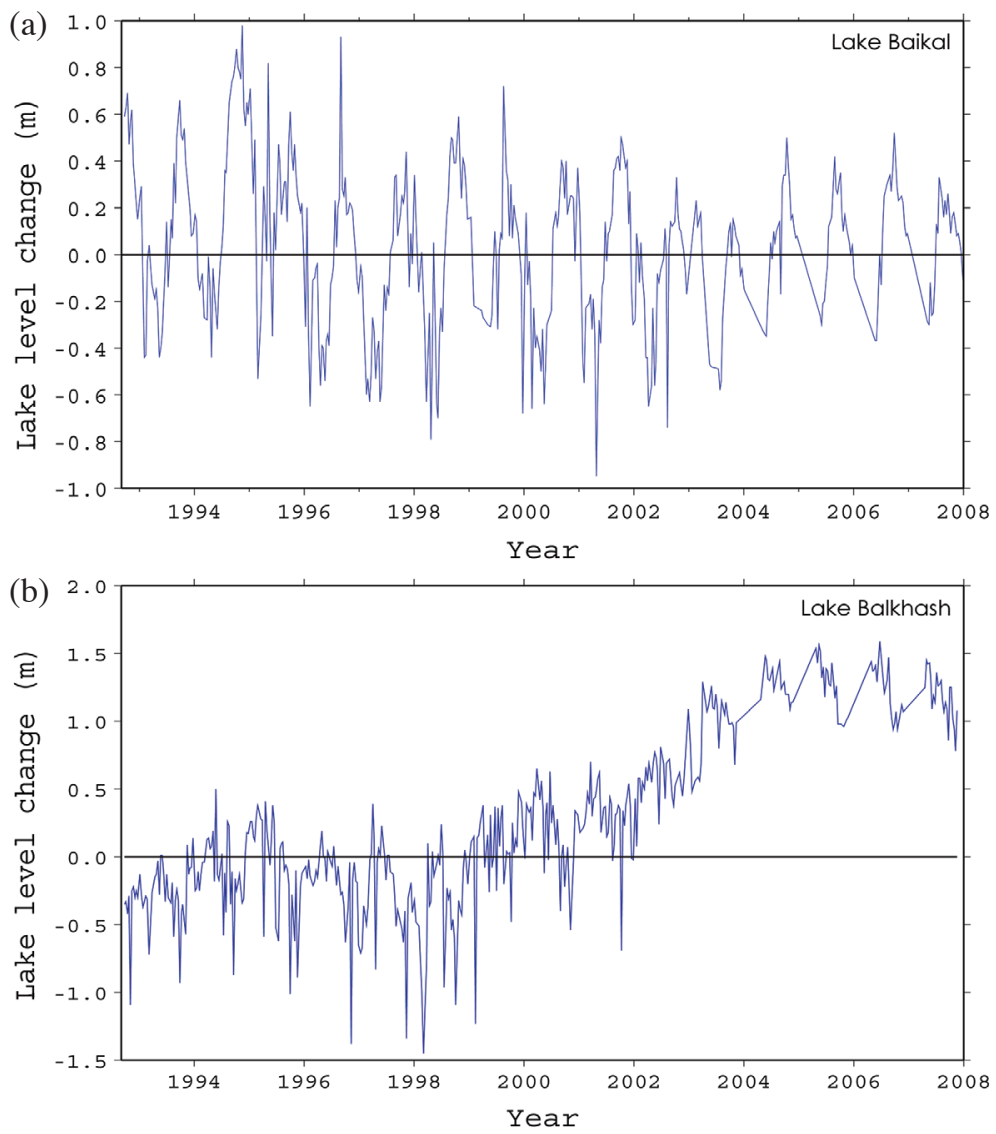

Fig. 3. Lake level changes from satellite altimetry over Lake Baikal (a) and Lake Balkhash (b).

Table 2. Rate of lake level changes over Lake Baikal and Lake Balkhash at selected time spans.

\begin{tabular}{ccccc}
\hline \multicolumn{2}{c}{ Lake Baikal } & & \multicolumn{2}{c}{ Balkhash } \\
\cline { 1 - 2 } Time span & Rate $\left(\mathbf{c m ~ y r} \mathbf{~ r}^{-1}\right)$ & & Time span & Rate $\left(\mathbf{c m ~ y r}^{-1}\right)$ \\
\hline $10 / 1992-10 / 1994$ & 6.7 & & $10 / 1992-4 / 1995$ & 18.8 \\
$10 / 1994-10 / 1996$ & -27.3 & & $4 / 1995-4 / 1998$ & -14.1 \\
$10 / 1996-10 / 2003$ & 0.5 & & $4 / 1998-4 / 2005$ & 23.0 \\
$10 / 2003-10 / 2007$ & 2.1 & $4 / 2005-4 / 2007$ & -3.6 \\
\hline
\end{tabular}


et al. 2007). In this paper, the Gaussian filtering with a $800-\mathrm{km}$ radius was applied to both GRACE and LDAS fields. To see whether the filters were properly applied and whether the signal reduction due to filtering was too large, the resulting GRACE gravity assessed by the result from the Land Data Assimilation System (LDAS) of the Climate Prediction Center (CPC), NOAA. As a product, LDAS contains EWHs on a $1^{\circ} \times 1^{\circ}$ grid. Rainfall, solar flux, radiation, atmospheric pressure, humidity and temperatures are among the factors considered in modeling LDAS. AS an example, Fig. 4 compares the EWHs from GRACE and LDAS in June 2007 over the two lakes. The two fields in Fig. 4 are similar in patterns, but there exist differences between them. In general, the water heights are positive in the western $\mathrm{Si}$ - beria, and decrease towards Mongolia. The smallest water height occurs near Lake Hulun (approximate latitude and longitude: $50^{\circ} 6^{\prime}$ and $115^{\circ} 5^{\prime}$ ) in the northeast China. Also, the LDAS field matches better with the GRACE over Lake Balkhash than over Lake Baikal. The stripes that exist in the raw GRACE gravity have also been effectively reduced by filtering. Before filtering the GRACE-derived water height ranges from -24.0 to 19.7 , which are reduced to -14 to $13 \mathrm{~cm}$ after filtering.

Figure 5 shows the distribution of rates of gravity change from GRACE from 2002 to 2009 over the two lakes. The rate of gravity change ranges from -0.5 to $0.5 \mu \mathrm{gal} \mathrm{yr}^{-1}$ with a low over the Tian Shan and a high over western Lake Baikal. Figure 6 shows the distributions of the amplitudes

(a)

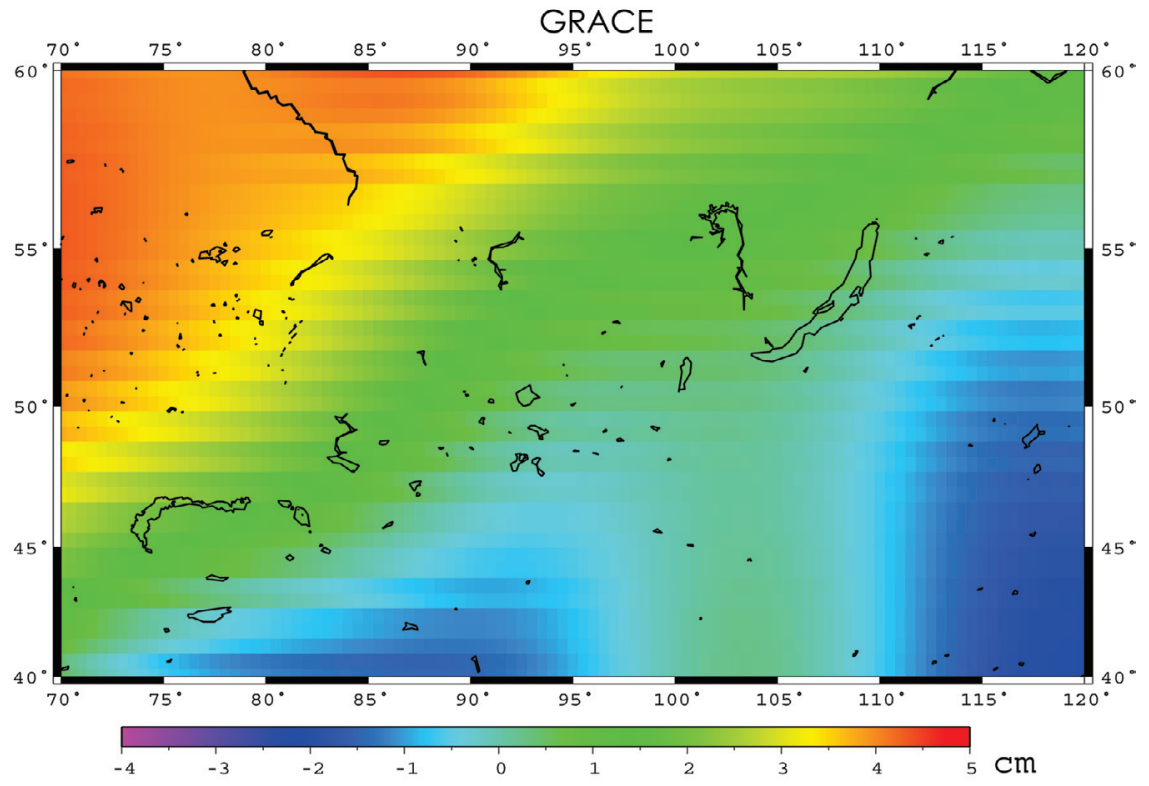

(b)

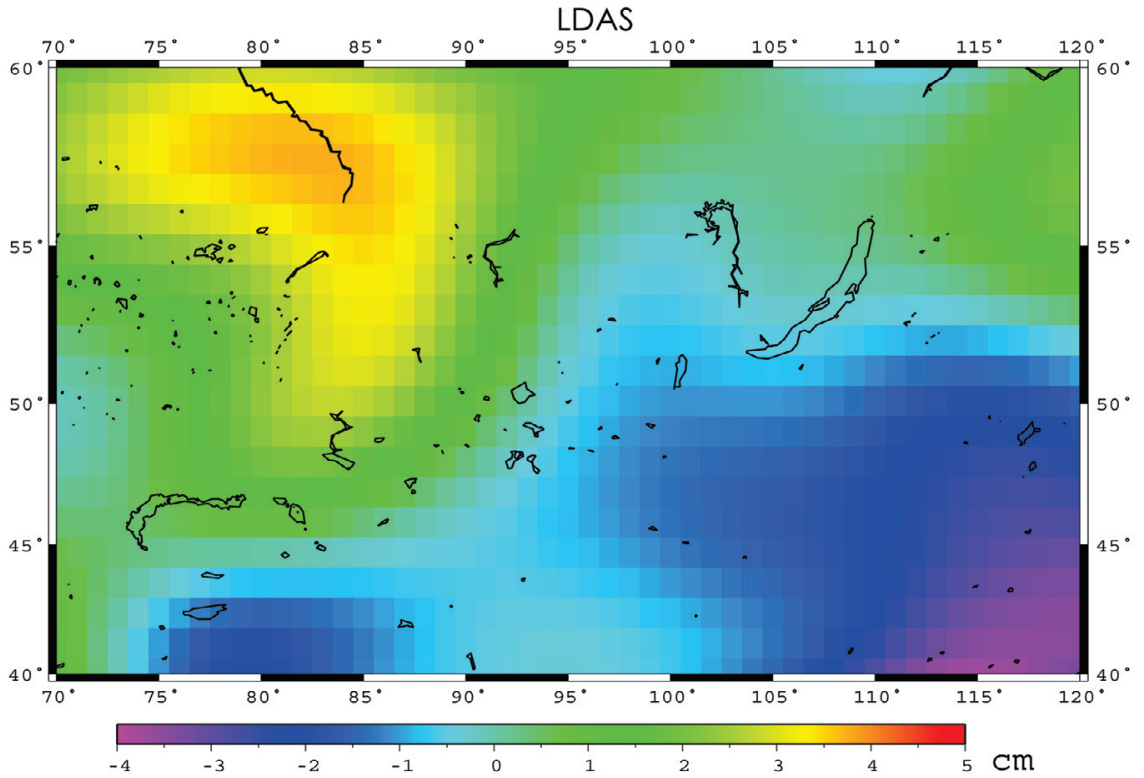

Fig. 4. Equivalent water heights (relative to a mean field) from GRACE (a) and LDAS (b) in June 2007. 


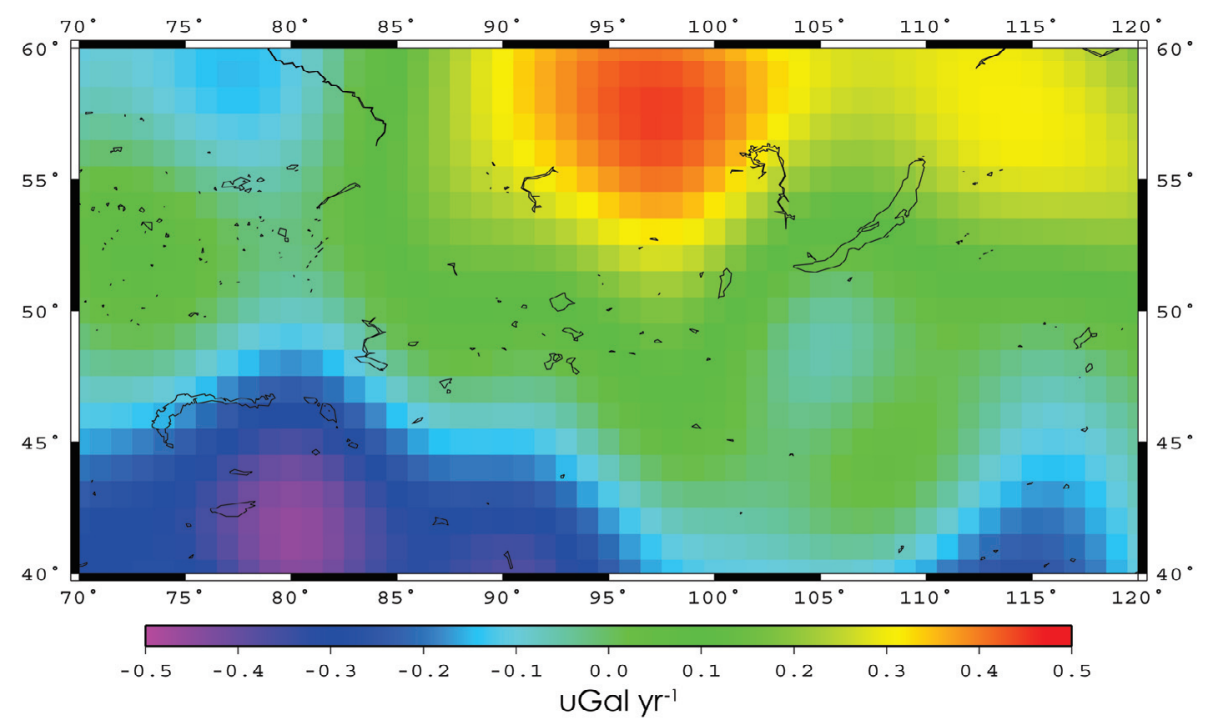

Fig. 5. Rates of gravity change from GRACE over Lake Baikal and Lake Balkhash.

(a)

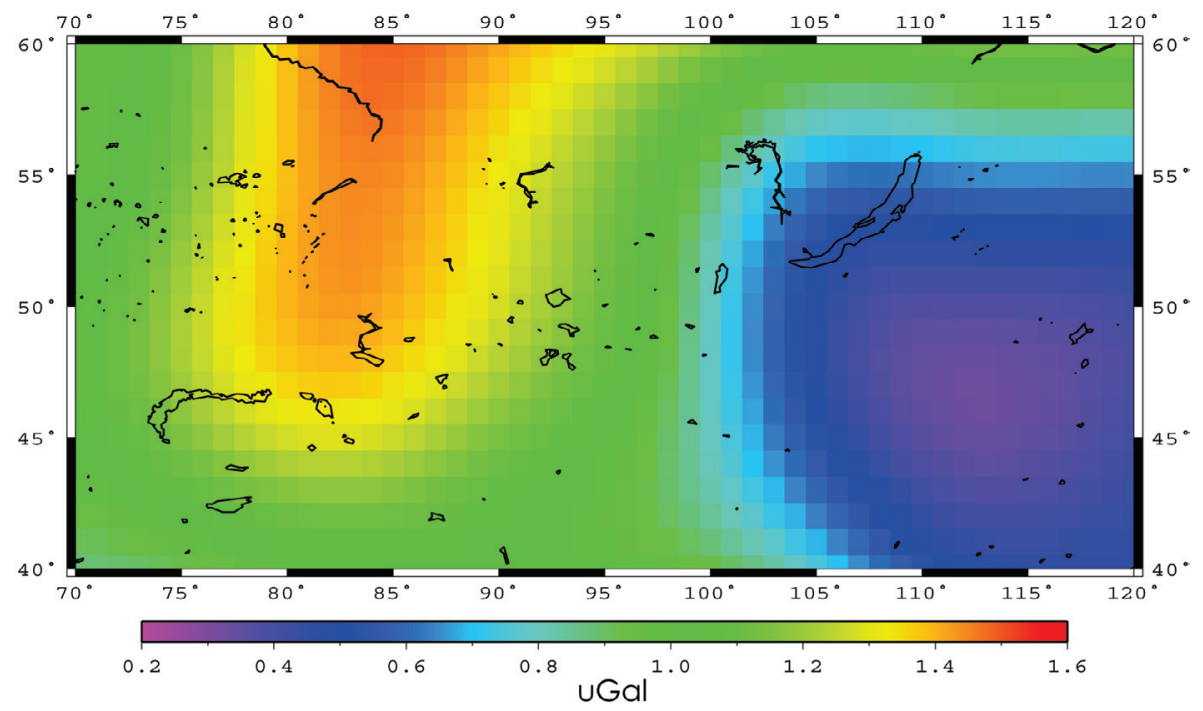

(b)

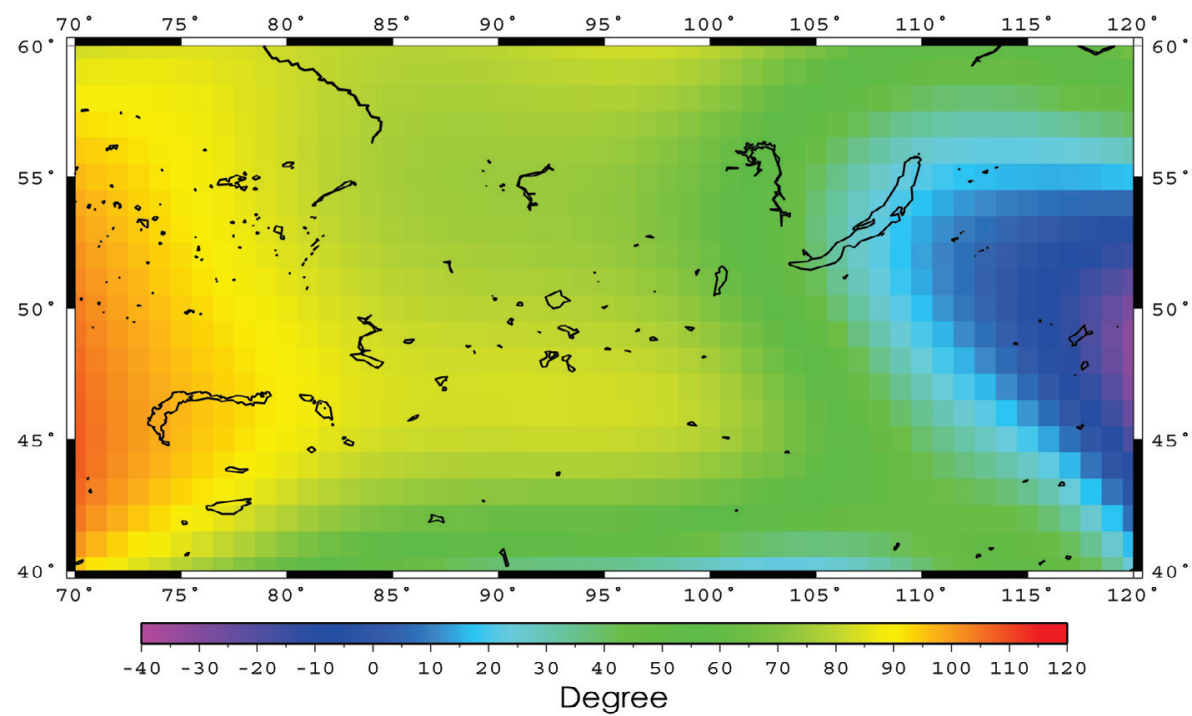

Fig. 6. Amplitude (a) and phase (b) of annual gravity change from GRACE. 
and phases of the annual variation of the EWH. Figure 6 suggests that the annual fluctuation over Lake Balkhash (largest: $1.5 \mu \mathrm{gal}$ ) is larger than that over Lake Baikal (largest: $0.8 \mu \mathrm{gal})$. The phases of the annual fluctuations over the two lakes differ by up to 100 arc-degrees, which translate to about 100 days. This implies that the peak of the EWH over Lake Balkhash occurs about 3 months before the peak over Lake Baikal.

\section{TOTAL MASS CHANGES OVER LAKE CATCH- MENTS FROM GRACE}

The total mass change in a lake catchment can be computed by integrating EWHs over the catchment as

$$
W=\rho_{W} \int_{C} h_{c} d A
$$

where " $C$ " indicates water catchment area, $d A$ is area element and $h_{c}$ is EWH from GRACE or LDAS. For numerical computations, we sub-divide the water catchment area into $1^{\circ} \times 1^{\circ}$ cells, each having an individual EWH. Figure 7 shows the borders of the water catchments and the $1^{\circ} \times 1^{\circ}$ cells over Lakes Baikal and Balkhash. The borders are defined by Swiercz (2004) and Kezer and Matsuyama (2006) for Lakes Baikal and Balkhash, respectively. The total mass change can be expressed as

$$
W=\rho_{W} \sum_{i=1}^{K} h_{i} \times A_{i}
$$

(a)

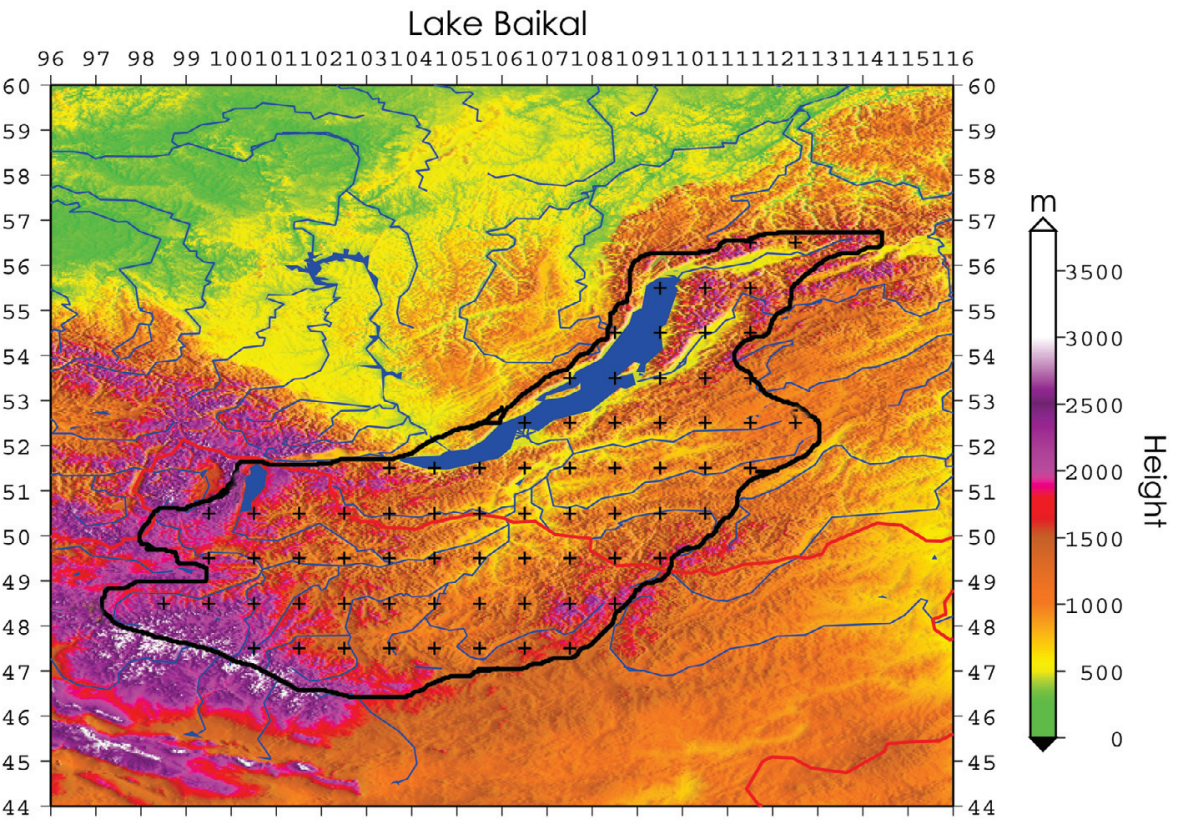

(b)

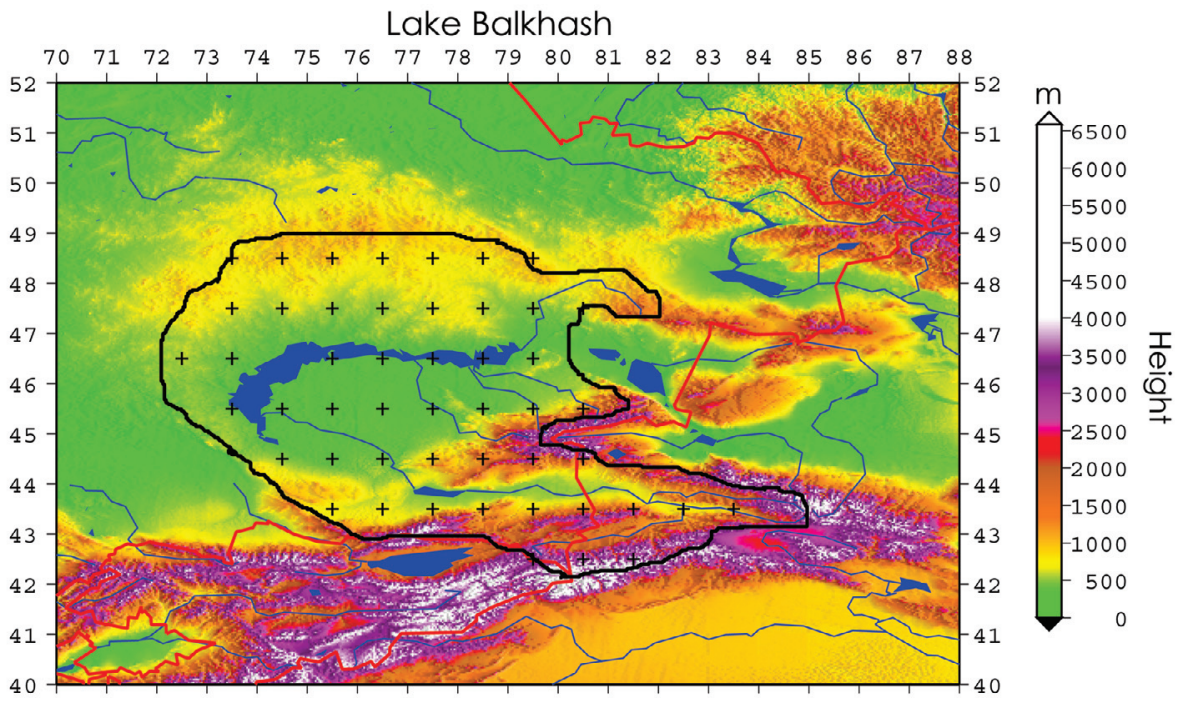

Fig. 7. Borders (thick lines) of the water catchments over Lake Baikal (a) and Lake Balkhash (b). Cross represents the center of the cell for integration. 
where $i$ is the index of the cell and $K$ is the total number of the cells. If we assume that a portion of the total water mass is transferred to the lake, then LLC, $h_{L}$ can also be derived as

$$
h_{L}=\frac{W F}{A_{L}}
$$

where $A_{L}$ is the area of the lake and $F$ is the ratio between the mass change over the lake and the mass change over the catchment (including the former). Over a sufficiently long time, the change of mass over a lake and its catchment may reach a balancing state, so that the ratio $F$ can be determined by the relation between the rate of LLC (from satellite altimetry) and the rate of gravity change (from satellite gravimetry or hydrological model) as

$\frac{d h_{L}}{d t}=\frac{F}{A_{L}} \frac{d W}{d t}$

Using LLCs (section 2) and gravity changes (section 3) determined in this paper, we find that the $F$ values are 0.6 and 0.3 for Lake Baikal and Lake Balkhash, respectively. Figure 8 compares the LLCs from satellite altimetry, GRACE and LDAS. Satellite gravimetry [see Eq. (6)] based on such $F$ values. The $F$ values (0.6 and 0.3 ) are applied to both the GRACE and the LDAS water height models to compute LLCs. The three data sets all show that LLCs contain variations at time scales ranging from few months to few years. For both lakes, the phase of LLC from LDAS matches better with the phase from satellite altimetry than that from GRACE.

\section{LAKE LEVEL CHANGE AND CLIMATE CHANGE}

The altimeter result (section 2) shows that LLCs over Lake Baikal and Lake Balkhash have different phases, and this is mainly attributed to the difference in the sizes of the water catchments and the difference in the local climates (Table 1). Figure 9 shows the mean monthly precipitations over Lake Baikal from 1951 to 1980 . The choice of this period is purely based on the availability of such data. The meteorological records at Irkutsk (near Lake Baikal) show that a high of rainfall occurs in July, and a low occurs in February. Lake Baikal is covered with ice from November to next March, and the ice melts from April to October. Thus, the water catchment of Lake Baikal stores the snow from November to March and does not contribute to the increase of lake level of Lake Baikal. This leads to a low of LLC of Lake Baikal in April. From April onward, the melting snow and rainfall combine to increase the lake level of Lake Baikal, resulting in a high in October. This discussion was also presented in Vyruchalkina (2004).

The climate over Lake Balkhash is between arid and semi-arid (Table 1). Figure 9 also shows the mean monthly precipitation over Lake Balkhash from 1986 to 1990. Compared to the pattern of precipitation over Lake Baikal, the rainfall of Lake Balkhash spreads over the entire year. Lake Balkhash is covered by ice from November to February, and the ice in the water catchment starts to melt in March. Although rivers such as Ili, Karatal, Aksu and Lepsi Rivers originating from Tian Shan and contribute to the water of Lake Balkhash, the lake level of Lake Balkhash is largely affected by precipitations in the water catchment (Vyruchalkina 2004).

Figure 10 compares mean monthly temperatures between two selected periods of time over Lake Baikal and Lake Balkhash. For both lakes, the monthly temperatures in the second (latter) period are always higher than those in the first period (except July for Lake Balkhash). Over Lake Bai$\mathrm{kal}$, the yearly mean temperature in $1951-1980$ is $-0.30^{\circ} \mathrm{C}$, but it becomes $0.34^{\circ} \mathrm{C}$ over 1998 - 2007. This reversal of the sign in temperature is equivalent to change of water state from solid to liquid, and is probably the result of global warming. Also, the increase of the yearly mean temperature in 1998 - 2007 may trigger melting of permafrost surrounding Lake Baikal, which in turn contributes additional water to the catchment of Lake Baikal. Furthermore, the average rate of LLC is negative over 1992 - 1998 (see Fig. 3), but it is positive in 1998 - 2007. The change of the sign of the LLC rate concurred with the change of the sign of temperature in 1998. Note that there was an El Niño event in 1997 - 1998 that was associated with the reversal of the rate of the second zonal gravity harmonic coefficient $\mathrm{J}_{2}$ (Chao et al. 2003). Over Lake Balkhash, the change of yearly mean temperature is slightly larger: it is $6.0^{\circ} \mathrm{C}$ in $1976-1992$ and $6.7^{\circ} \mathrm{C}$ in 1998 - 2007. This change of temperature is associated with the change of LLC after 1998 (Fig. 3). Because the water catchment over Lake Balkhash is less developed than that over Lake Balkhash, the variation of lake level at Lake Baikal is mostly caused by the increase of precipitation, melting of permafrost and snow.

\section{CONCLUSIONS}

This paper presents changes of lake level and water storages over Lake Baikal and Lake Balkhash based on measurements from satellite altimetry, satellite gravimetry (GRACE) and a hydrological model (LDAS). The result may be useful in establishing water balance models over these two lakes. Several assumptions were made when deriving LLCs from the GRACE and LDAS results, leading to the ratios of 0.6 and 0.3 between the mass change of the lake and its catchment for Lake Baikal and Lake Balkhash. Despite different accuracies and spatial resolutions, certain common features in LLCs from such three data sets are evident. For example, the trends and the inter-annual variations of LLCs from all data sets match those with the temperature 
(a)

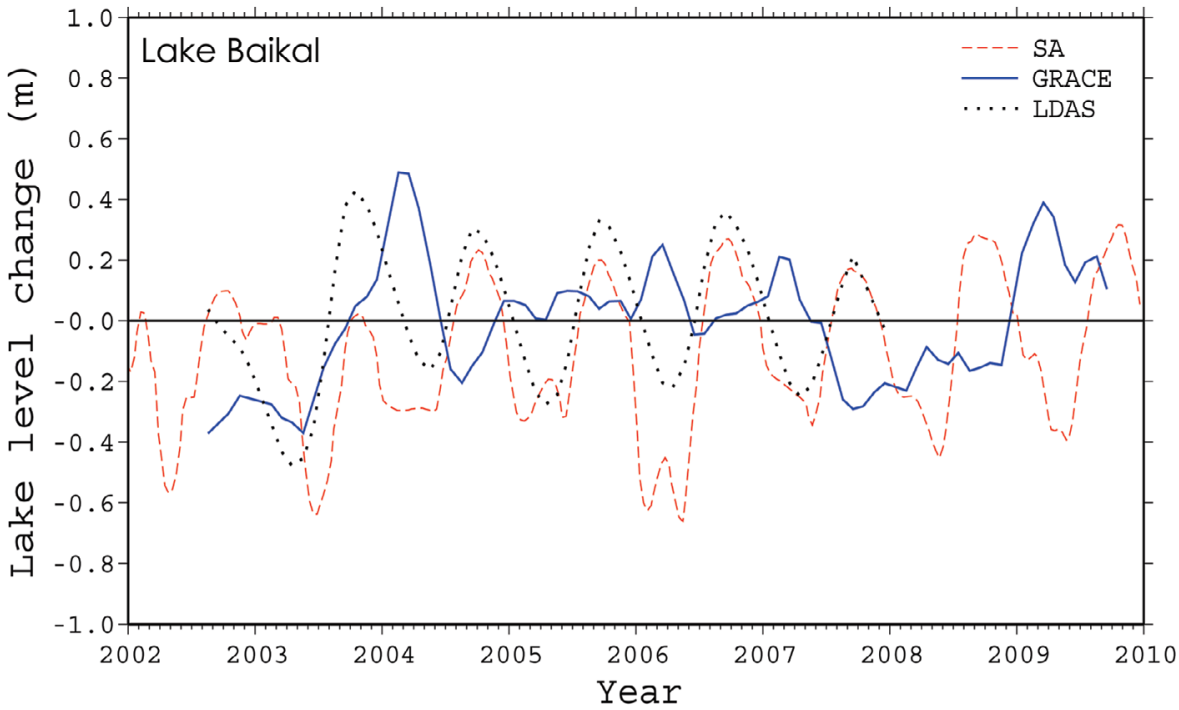

(b)

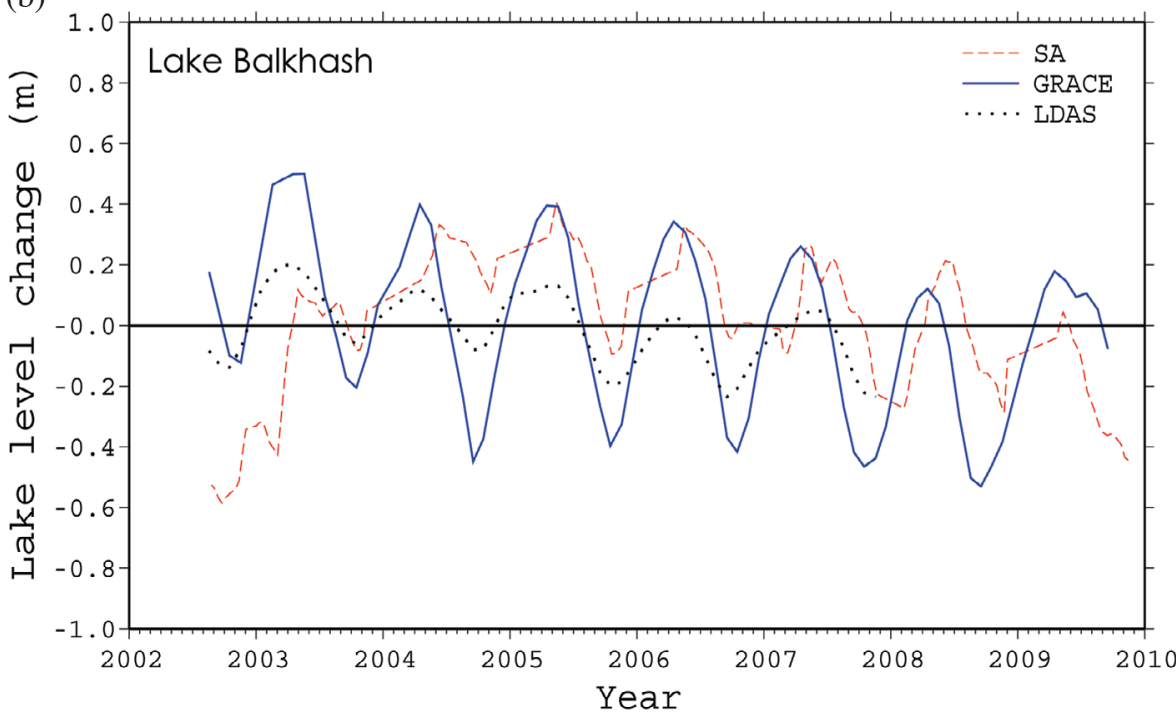

Fig. 8. Lake level changes from satellite altimetry, GRACE gravity and LDAS model over Lake Baikal (a) and Balkhash (b).

(a)

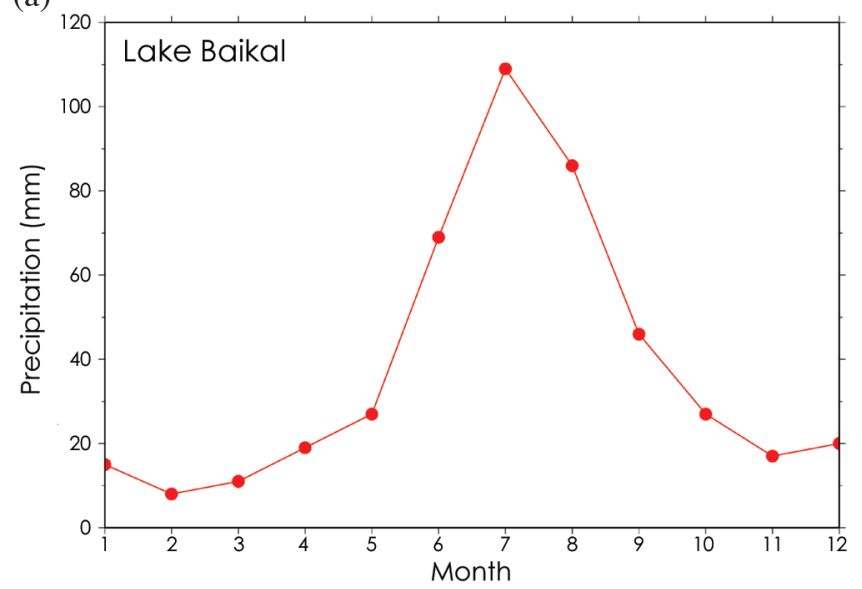

(b)

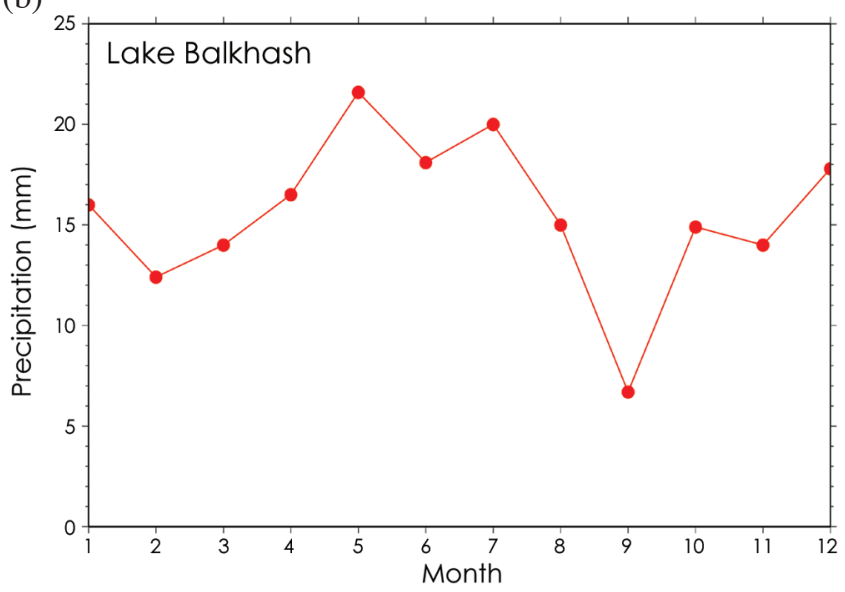

Fig. 9. Mean monthly precipitation (at Irkutsk) over Lake Baikal (a) from 1951 to 1980, and Lake Balkhash (b) from 1986 to 1990. 
(a)

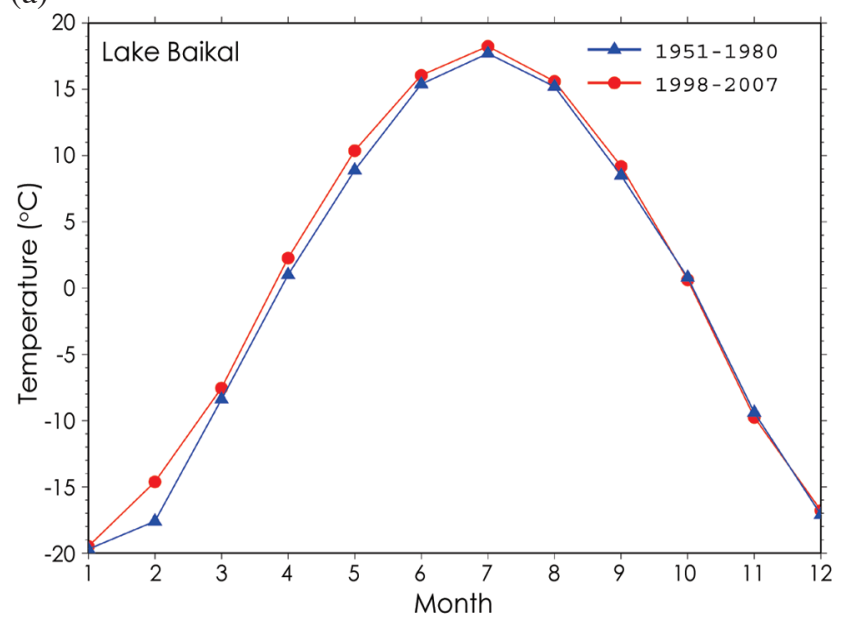

(b)

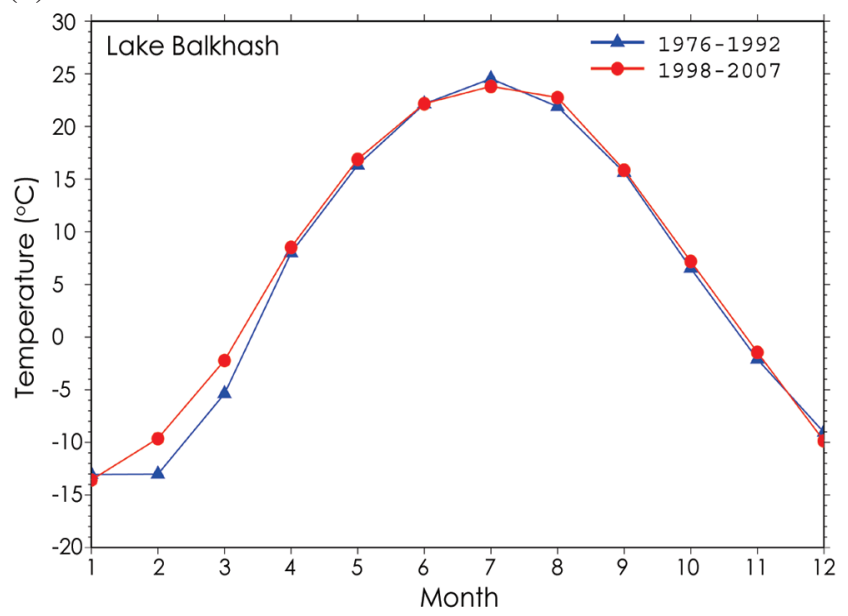

Fig. 10. Mean monthly temperatures (at Irkutsk) over Lake Baikal (a) for two periods: (1) 1951 - 1980 and (2)1998 - 2007, and over Lake Balkhash (b) for two periods: (1) 1976 - 1992 and (2) 1998 - 2007.

records. One large difference between the altimetry-derived LLCs and the gravimetry-derived LLCs is in the phase of the annual variation, and this difference is about 100 days over Lake Baikal. The LLCs reveal certain signatures of climate change that are also clearly shown by the precipitation and temperature records over the two lakes. More space and ground-based observations are needed to see the mechanisms of the climate change over these two lakes.

Acknowledgements The altimetry lake level data are from the USDA/FAS/OGA and NASA Global Agriculture Monitoring (GLAM) Project. This study is supported by the National Science Council and National Space Organization (NSPO) of Taiwan.

\section{REFERENCES}

Andersen, O. B. and J. Hinderer, 2005: Global inter-annual gravity changes from GRACE: Early results. Geophys. Res. Lett., 32, L01402, doi: 10.1029/2004GL020948. [Link]

Bedient, P. B. and W. C. Huber, 2002: Hydrology and Floodplain Analysis. Prentice Hall.

Berry, P. A. M., H. Bracke, and A. Jasper, 1997: Retracking ERS-1 Altimeter Waveforms over Land: An Expert System Approach. The $3^{\text {rd }}$ ERS Symposium, 14-21 March.

Birkett, C. M., 1995: The contribution of TOPEX/POSEIDON to the global monitoring of climatically sensitive lakes. J. Geophys. Res., 100, 25179-25204, doi: 10.1029/95JC02125. [Link]

Birkett, C. M., 1998: Contribution of the TOPEX NASA Radar Altimeter to the global monitoring of large rivers and wetlands. Water Resour. Res., 34, 1223-1239, doi: 10.1029/98WR00124. [Link]

Chambers, D. P., 2006: Evaluation of new GRACE timevariable gravity data over the ocean. Geophys. Res. Lett., 33, L17603, doi: 10.1029/2006GL027296. [Link]

Chambers, D. P., J. Wahr, and R. S. Nerem, 2004: Preliminary observations of global ocean mass variations with GRACE. Geophys. Res. Lett., 31, L13310, doi: 10.1029/2004GL020461. [Link]

Chao, B. F., A. Y. Au, J.-P. Boy, and C. M. Cox, 2003: Time-variable gravity signal of an anomalous redistribution of water mass in the extratropic Pacific during 1998-2002. Geochem. Geophys. Geosyst., 4, 1096, doi: 10.1029/2003GC000589. [Link]

Chen, J. L., C. R. Wilson, B. D. Tapley, and J. C. Ries, 2004: Low degree gravitational changes from GRACE: validation and interpretation. Geophys. Res. Lett., 31, L22607, doi: 10.1029/2004GL021670. [Link]

Chen, J. L., C. R. Wilson, J. S. Famiglietti, and M. Rodell, 2007: Attenuation effect on seasonal basin-scale water storage changes from GRACE time-variable gravity. $J$. Geodesy, 81, 237-245, doi: 10.1007/s00190-006-01042. [Link]

Crétaux, J.-F. and C. Birkett, 2006: Lake studies from satellite radar altimetry. C. R. Geosci., 338, 1098-1112, doi: 10.1016/j.crte.2006.08.002. [Link]

Davis, J. L., P. Elósegui, J. X. Mitrovica, and M. E. Tamisiea, 2004: Climate-driven deformation of the solid Earth from GRACE and GPS. Geophys. Res. Lett. 31, L24605, doi: 10.1029/2004GL021435. [Link]

Gordon, W. S. and J. S. Famiglietti, 2004: Response of the water balance to climate change in the United States over the $20^{\text {th }}$ and $21^{\text {st }}$ centuries: Results from the VEMAP Phase 2 model intercomparisons. Global Biogeochem. Cycles, 18, GB1030, doi: 10.1029/2003GB00 
2098. [Link]

Han, S. C., C. K. Shum, C. Jekeli, and D. Alsdorf, 2005: Improved estimation of terrestrial water storage changes from GRACE. Geophys. Res. Lett., 32, L07302, doi: 10.1029/2005GL022382. [Link]

Hwang, C., M. F. Peng, J. Ning, J. Luo, and C. H. Sui, 2005: Lake level variations in China from TOPEX/Poseidon altimetry: Data quality assessment and links to precipitation and ENSO. Geophys. J. Int., 161, 1-11, doi: 10.1111/j.1365-246X.2005.02518.x. [Link]

Hwang, C. and Y. C. Kao, 2006: Spherical harmonic analysis and synthesis using FFT: Application to temporal gravity variation. Comput. Geosci., 32, 442-451, doi: 10.1016/j.cageo.2005.07.006. [Link]

Hwang, C., J. Benveniste, Y. M. Dang, and C. K. Shum, 2008: Preface to the special issue on satellite altimetry over land and coastal zones: Applications and challenges. Terr. Atmos. Ocean. Sci., 19, I, doi: 10.3319/ TAO.2008.19.1-2.I(SA). [Link]

Jekeli, C., 1981: Alternative Methods to Smooth the Earth's Gravity Field. Department of Geodetic Science and Surveying, Ohio State University, Columbus, $\mathrm{OH}$.

Kezer, K. and H. Matsuyama, 2006: Decrease of river runoff in the Lake Balkhash basin in Central Asia. Hydrol. Process., 20, 1407-1423, doi: 10.1002/hyp.6097. [Link]

Seo, K.-W. and C. R. Wilson, 2005: Simulated estimation of hydrological loads from GRACE. J. Geodesy, 78, 442-
456, doi: 10.1007/s00190-004-0410-5. [Link]

Swenson, S. and J. Wahr, 2006: Post-processing removal of correlated errors in GRACE data. Geophys. Res. Lett., 33, L08402, doi: 10.1029/2005GL025285. [Link]

Swenson, S. and J. Wahr, 2009: Monitoring the water balance of Lake Victoria, East Africa, from space. J. Hydrol.,370, 163-176,doi:10.1016/j.jhydrol.2009.03.008. [Link]

Swiercz, S., 2004: GIS supported characterization of the Baikal region. Diploma Thesis, Free University of Berlin, Germany.

Tapley, B. D., S. Bettadpur, J. C. Ries, P. F. Thompson, and M. M. Watkins, 2004: GRACE Measurements of mass variability in the Earth system. Science, 305, 503-505, doi: 10.1126/science.1099192. [Link]

Vyruchalkina, T. Y., 2004: Lake Baikal and the Angara River before and after the construction of reservoirs. Water Resour., 31, 483-489, doi: 10.1023/B:WARE.00 00041916.49909.d0. [Link]

Wahr, J., M. Molenaar, and F. Bryan, 1998: Time variability of the Earth's gravity field: Hydrological and oceanic effects and their possible detection using GRACE. J. Geophys. Res., 103, 30205-30229, doi: 10. 1029/98JB02844. [Link]

Wahr, J., S. Swenson, V. Zlotnicki, and I. Velicogna, 2004: Time-variable gravity from GRACE: First results. Geophys. Res. Lett., 31, L11501, doi: 10.1029/2004GL019 779. [Link] 